\title{
FORMULATION DEVELOPMENT AND IN VITRO EVALUATION OF CURCUMIN-LOADED SOLID SELF-NANOEMULSIFYING DRUG DELIVERY SYSTEM FOR COLON CARCINOMA
}

\author{
CHENMALA KARTHIKA, RAMAN SURESHKUMAR*, AMEER SUHAIL
}

Department of Pharmaceutics, JSS College of Pharmacy (Affiliated to JSS Academy of Higher Education and Research), Ooty, Tamil Nadu, India. Email: sureshcoonoor@jssuni.edu.in

Received: 25 March 2019, Revised and Accepted: 28 May 2019

\begin{abstract}
Objective: Cancer is the deadliest disease affecting the life of the people all around the world. Colon cancer is the cancer which is affecting the colon region it is the last part of the gastrointestinal tract which is mainly responsible for the absorption of water and minerals from the food debris. Colon cancer is the second most cancer creating death in the world. It affects both male and female equally. Curcumin is a flavonoid used from decades for the treatment of various ailments including cancer. This present work is to formulate Self-nanoemulsifying drug delivery (SNEDDS) system with the help of curcumin for colon delivery.
\end{abstract}

Materials and Methods: Nanoemulsion was prepared using the curcumin pre-concentrated self-nanoemulsifying drug delivery system, with which tablets were prepared and coated with pectin followed by the evaluation test such as in vitro dissolution and cell line studies.

Results: Solubility profile of curcumin was found with a greater impact using Capmul MCM and Labrafac PG which is then added with the surfactants and co-surfactants and were converted into Nano-droplets. F1 formulation was selected after carrying out the characterisation studies and converted into a tablet dosage form and then coated with pectin, in vitro studies depicted a release of $80 \%$ in $\mathrm{pH} 6.8$.

Conclusions: Formulation of a solid self-Nano emulsifying drug delivery system using curcumin was successfully carried out. From the results obtained, the formulation (F1) was selected for the formation of the tablets and the further experimental part is carried out. The tablet dosage form is then coated with pectin and used for targeting the colon cancer cells for its treatment.

Keywords: Colon cancer, Curcumin, Pectin, Self-nanoemulsifying drug delivery system.

(C) 2019 The Authors. Published by Innovare Academic Sciences Pvt Ltd. This is an open access article under the CC BY license (http://creativecommons. org/licenses/by/4. 0/) DOI: http://dx.doi.org/10.22159/ajpcr.2019.v12i7.33231

\section{INTRODUCTION}

Colorectal cancer also coined as colon cancer or rectal cancer is the development of cancer in the colon or rectal region which is one of the leading causes of death in this world. The results of the modern lifestyle, lack of exercise, and alcohol consumption lead to an increase in the number of colorectal cancer worldwide; hence, there is a need for developing a novel and environmentally benign drug therapy for the development of colorectal cancer [1]. The use of the herbal ingredient to treat and for the prevention of cancer is helpful in terms of its biocompatibility, biodegeneration, and non-toxic effect. Flavonoids are the compounds which are commonly extracted from different parts of the plant which are mostly used for the treatment of the colon cancer [2]. The antioxidant content present in them is the major reason behind this phenomenon. Curcumin found in turmeric has a potent power to self-destruct colon cancer cells [3]. The adverse effects caused by the chemotherapeutic drugs such as hair loss, damage to the cells in the mouth, digestive tract, and reproductive tract, weight changes could be minimized to an extent by introducing curcumin in the therapy $[4,5]$. The easy availability and the safety in administration even at a higher dose provide an additional advantage of using curcumin in the treatment. Curcumin belongs to the biopharmaceutical classification system (BCS) Class II system with a poor solubility nature. The solubility issues could be managed using the lipid drug formulation approach [6,7]. To increase the solubility of the drug in the gastrointestinal tract and also to increase the bioavailability of Class 2 and Class 4 drugs, lipid-based drug delivery system (LBDDS) has been adopted. In LBDDS, the most common approach is the incorporation of the drug compound in the lipid vehicles such as oils, and surfactant and cosurfactant ( $\mathrm{SCoS}$ ) to form a nanoemulsion (NE). The later mixture is typically called self-dispersing system often referred to as a self-emulsifying drug delivery system or self-nanoemulsifying drug delivery system (SNEDDS) [8-10].

Oral drug delivery system is the most preferred and convenient option for cancer treatment. At present, pharmaceutical solid dosage form includes tablets, granules, capsules, and spheroids and among those tablets account for $70 \%$ of all the approved pharmaceutical solid dosage forms [11]. The $\mathrm{pH}$ range in the gastrointestinal is actively used as a targeted mechanism and for the dissolution and the release polymers. In our approach, the tablet formulation is coated with the polymer pectin. The $\mathrm{pH}$ variation throughout the organs in the gastrointestinal tract is used for the drug delivery by an enteric coating [12]. To over the aboveexplained barriers during the therapy, this formulation was developed to provide an effective and efficient therapy for the treatment of colon cancer and to provide specificity at the site of action.

\section{MATERIALS AND METHODS}

\section{Reagents}

Curcumin and pectin were purchased from HiMedia Ltd., India. Capmul MCM, Labrasol, Transcutol HP, Kolliphor, Labrafil M, and Labrafac PG were obtained as a gift sample from Gattefosse India Pvt. Ltd., Mumbai. Castor oil, olive oil, and linseed oil were obtained from Sigma Ltd., India.

\section{Solubility studies}

The solubility of the curcumin in various oils (Capmul MCM, oleic acid, linseed oil, castor oil, Labrafac PG, olive oil, corn oil, and soybean oil), surfactants (Labrasol and Kolliphor), and cosurfactants (Transcutol HP and Labrafil M) was performed by the shake flask method. UV spectroscopy at a wavelength of $428 \mathrm{~nm}$ was used to determine the concentration of the drug dissolved [13]. 
Formulation of NE by spontaneous emulsification method

The different ratio of Smix from 1:1 to 1:9 was prepared and individually mixed with the different proportions of oil and titrated against the water until a translucent to transparent liquid is obtained $[14,15]$

\section{Evaluation of NE}

Particle size distribution, zeta potential, and polydispersity index (PDI)

Particle size distribution, zeta potential, and PDI of the prepared formulation of NE were found out using dynamic light scattering technique. Malvern Zetasizer Nano Series ZEN1002 (Malvern, UK) was the instrument used in a cuvette DTS0012 in the wavelength of $532 \mathrm{~nm}$ which comprised green laser and had scattering angle of $173^{\circ} \mathrm{C}$ [16].

\section{Preparation of curcumin pre-concentrated SNEDDS}

The oil in which concentration is maximum soluble was used similarly to the Smix combination of surfactant:cosurfactants (Kolliphor:Labrasol):transcutol, respectively $[17,18]$. Pre-concentrate SNEDDS was prepared, containing a fixed proportion of curcumin dissolved in a mixture of vehicles. About $40 \mathrm{mg}$ of curcumin drug was accurately weighed and dissolved in oils using a magnetic stirrer until a homogenous solution was formed to this SCoSs were added. The resultant pre-concentrate solution was vortexed for $10 \mathrm{~min}$ and kept in the Orbital Shaker for $24 \mathrm{~h}$. This pre-concentrated was used for the preparation of tablets [19-21].

Preparation of curcumin pre-concentrated SNEDDS-loaded tablets Curcumin containing SNEDDS incorporated tablets were performed by the direct compression technique. For preparing curcumin tablets, the optimized oil and Smix used for formulating curcumin pre-concentrate were used as the vehicle. Six formulations of SNEDDS tablets (T1-T6) were prepared with a fixed proportion of curcumin dissolved in a mixture of oil liquid and mixed with solid pharmaceutical excipients. The solid excipients used were the mixture of Neusilin or Kolliphor or anhydrous dextrose, magnesium stearate, and talc.

\section{Coating of curcumin tablet SNEDDS}

The fabricated coating pan was used for coating the prepared tablets with pectin $(1 \%)$. The polymeric weight gain was calculated and used for the assessment of the morphology of coating. After the coating, the tablets were cured in an oven for $2 \mathrm{~h}$ at $40^{\circ} \mathrm{C}$. Then, the prepared polymeric coated tablets were tested for drug release at various $\mathrm{pH}$ conditions [22].

\section{Characterization of curcumin pre-concentrate powders \\ Bulk density of pre-concentrate powders}

An accurately weighed quantity of mixtures of adsorbed powders was poured into the graduated cylinder and the bulk volumes were accurately measured before tapping and after tapping, bulk density was calculated separately using the formula [23-25].

Bulk density $=\mathrm{M} / \mathrm{vb}$

Where,

$\mathrm{M}=$ Mass of the spheroids and $\mathrm{vb}=$ Bulk volume

\section{Compressibility pre-concentrate powders}

Accurately weighed quantities of mixtures of adsorbed powders were poured into the graduated cylinder and the bulk volumes were noted before and after tapping. Using the tapped density value and the value of bulk density, Carr's index was calculated. The compressibility index of the adsorbed powder was evaluated by Carr's compressibility index using the formula.

Carr's index $=\frac{\text { Tapped density }- \text { bulk density }}{\text { Tapped density }} \times 100$

\section{The angle of repose pre-concentrate powders}

The fixed funnel method was used to check the flowability of the powder and to determine the angle of repose. The mixtures of the powder were poured into the funnel with the help of the apex conical pile so that the pile reaches the funnel's tip. The radius ( $r$ ) and height of the pile $(\mathrm{h})$ were then found out. The angle of repose $(\theta)$ for samples was determined using the following formula:

Tan-1= $(\mathrm{h} / \mathrm{r})=$ angle of repose

Where,

$\mathrm{H}=$ Height of heap of powder

$\mathrm{R}=$ Radius of the heap of the powder,

Therefore $=\tan -1(\mathrm{~h} / \mathrm{r})$

Evaluation of SNEDDS containing tablets

Friability

Roche friabilator tester (Electrolab, Mumbai, India) was the instrument used to find out the friability of the tablets. Ten tablets were used for testing the impact at $25 \mathrm{rpm}$ for about $4 \mathrm{~min}$. Then, the remaining particles were separated by sieving and the tablets on the sieve were weighed and the percentage friability was calculated from the difference of the tablets before and after friability testing.

Percentage of weight loss $(\%)=\frac{\text { weight loss }}{\text { initial weight of } 20 \text { tablets }} \times 100$

Hardness

Randomly 20 tablets were selected. Then, each tablet was tested for hardness using a hardness tester and the value at which the tablet breaks off was noted. From these values, the average tablet hardness and the variety of hardness were determined based on the standard deviation.

Diameter and thickness

Randomly 20 tablets were picked. Then, the diameter, as well as the thickness of the tablets, was checked individually using Vernier caliper.

\section{Weight variation}

Randomly 20 tablets were selected. Each tablet was weighed individually. The weight was noted. The average of the weights was calculated. The percentage deviation of the tablets was calculated from the average weight of the tablets.

Disintegration time

Six tablets were placed in different tubes of the basket and the basket was lifted up and down for $60 \mathrm{~min}$. Here $0.1 \mathrm{~N} \mathrm{HCl}$ and $6.8 \mathrm{pH}$ buffer were used as immersion fluid. The solutions were maintained at $37^{\circ} \mathrm{C} \pm$ $2^{\circ} \mathrm{C}$. The time at which each tablet disintegrates was noted.

\section{In vitro dissolution study}

The drug release standard for delayed release formulations (entericcoated tablets) was used to determine the in vitro release of the tablets. The same method as done by Sarasija and Hota was used by slightly modifying the $\mathrm{pH}$ medium, which was based on the different transit time starting from the stomach to the colon. USP paddle apparatus was used to carry out the dissolution studies (USP-XXIII-dilution method). Various $\mathrm{pH}$ conditions mimicking the in vivo conditions $\mathrm{pH} 1.2$ for $1 \mathrm{~h}$, $\mathrm{pH} 3.0$ for $1 \mathrm{~h}$, and $\mathrm{pH} 6.8$ for up to $3 \mathrm{~h}$ ) were optimized throughout the study period. About $500 \mathrm{ml}$ of $1.2 \mathrm{pH}$ buffer was poured into the basket and was pellets which were put into the medium and the paddle was rotated at $50 \mathrm{rpm}$. About $1 \mathrm{ml}$ of samples was withdrawn at determined time intervals and then was immediately replaced with the $1.2 \mathrm{pH}$ buffer of equal quantity. The temperature of $37^{\circ} \mathrm{C}$ was maintained inside the basket. The amount of drug release was determined using UV-visible spectrophotometer at a wavelength of $428 \mathrm{~nm}$ [26-30].

\section{Cell line study}

The effect of curcumin-loaded spheroid formulation on cell growth was found in human colon carcinoma, HT-29 cell line (National Centre for Cells studies, Pune). The cell growth inhibitory activity of 
the samples was performed using 3-(4, 5-dimethylthiazol-2-yl)-2,5diphenyltetrazolium bromide (MTT) colorimetric assay. The fractional absorbance was calculated by the following formula [30-32]:

$\%$ cell survival $=\frac{\text { Mean absorbance in test wells }}{\text { mean absorbance in control wells }} \times 100$

Statistical analysis

The results depicted that bellows are expressed as mean \pm deviation. The difference among the groups was calculated using Student's t-test. $\mathrm{p} \leq 0.05$ is considered to be statistically significant.

\section{RESULTS AND DISCUSSION}

\section{Solubility studies of the drug in different oils}

Solubility is considered as an important aspect in the formulation of NE, as the drug remains in liquid form solubilized in the oil phase. Therefore, the oil in which the drug exhibited maximum solubility was selected for the preparation of the formulation. From Table 1, it is evident that Capmul MCM:Labrafac PG (1:1) showed maximum solubility of curcumin $45.339 \mathrm{mg} / \mathrm{mL}$. Hence, Capmul MCM:Labrafac PG was selected for the formulation of NE. The increased solubility of the drug could be due to the more affinity toward the respective oil. Curcumin being a lipophilic drug which comes under BCS II drug, though lipophilic it is not soluble in all the oils. The drug is soluble in Capmul MCM:Labrafac PG which is a combination of medium chain triglycerides and macrogol. The combined solvent property of both macrogol and triglycerides influenced the increased solubility of the drug, as compared with that of oils such as Capmul MCM or Labrafac PG used as individually. The report clearly depicts the solubility profile in other oils are comparatively low. In olive oil, the solubility profile was found to be only $3.8 \mathrm{mg} / \mathrm{ml}$. In other oils also, the solubility profile range was between 3 and $10 \mathrm{mg} / \mathrm{ml}$. When Capmul MCM and Capmul MCM + Labrafil were used as a solvent, the solubility profile was found to be $33.5 \mathrm{mg} / \mathrm{ml}$ and $32.61 \mathrm{mg} / \mathrm{ml}$, respectively. Hence, the oil which shown the higher solubility range which is $45.33 \mathrm{mg} / \mathrm{ml}$ was selected for further studies.

\section{Formulation of NE by spontaneous emulsification method}

To prevent the coalescence in the prepared NE, the concentration of the $\mathrm{SCoS}$ used plays a key role in the formation of the barrier at the interface. Smix gets adsorbed at the interface, reducing the energy

Table 1: Solubility studies of curcumin using different oils

\begin{tabular}{ll}
\hline Oils & Curcumin $(\mathbf{m g} / \mathbf{m l})($ mean \pm SD) \\
\hline Olive oil & $3.8 \pm 0.5$ \\
Soybean oil & $3.56 \pm 0.8$ \\
Labrafac PG & $22.87 \pm 0.56$ \\
Capmul MCM & $33.5 \pm 0.25$ \\
Corn oil & $5.46 \pm 0.5$ \\
Peanut oil & $3.74 \pm 0.5 \pm 0.8$ \\
Linseed oil & $4.21 \pm 0.5$ \\
Capmul MCM+Labrafac PG & $45.33 \pm 1.5$ \\
Capmul MCM+Labrafil & $32.61 \pm 0.25$ \\
\hline
\end{tabular}

SD: Standard deviation

Table 2: The visual observations during aqueous phase titration using SCoS 1:1-1:3 are recorded

\begin{tabular}{llllllllll}
\hline \multirow{2}{*}{ SCoS } & \multicolumn{2}{l}{ 0il: SCoS } & & & & & & & \\
\cline { 2 - 9 } & F1 & F2 & F3 & F4 & F5 & F6 & F7 & F8 & F9 \\
\hline $1: 1$ & $1: 1$ & $1: 2$ & $1: 3$ & $1: 4$ & $1: 5$ & $1: 6$ & $1: 7$ & $1: 8$ & $1: 9$ \\
& NE & NE & NE & E & E & E & EG & EG & EG \\
$1: 2$ & $1: 1$ & $1: 2$ & $1: 3$ & $1: 4$ & $1: 5$ & $1: 6$ & $1: 7$ & $1: 8$ & $1: 9$ \\
& M & NE & NE & EG & E & M & E & NE & NE \\
$1: 3$ & $1: 1$ & $1: 2$ & $1: 3$ & $1: 4$ & $1: 5$ & $1: 6$ & $1: 7$ & $1: 8$ & $1: 9$ \\
& E & NE & NE & EG & EG & E & EG & E & M \\
\hline
\end{tabular}

NE: Nanoemulsion, E: Emulsion, EG: Emulsion gel, M: Milky required for NE formation, thus improving the thermodynamic stability of the NE formulation. In this method, the following observation was recorded. The visual observations during aqueous phase titration using SCoS 1:1-1:3 are recorded in Table 2.

In Smix ratio 1:1, when SCoSs are in equal ratio, the ratio of oil and Smix, i.e., from formulation (F1 to F3) translucent formation of NE was observed. In the Smix ratio 1:3, the ratio of oil and SCoS, i.e., from formulation (F2 to F3 and F8 to F9) translucent formation of NE was observed and a final ratio of $\mathrm{S} \operatorname{CoS} 1: 4$, the ratio of oil and Smix from formulation (F3 to F9) only milky and emulsion gel was observed. Therefore, 1:1 ratio of Smix having formulation (F1) was selected for further studies. In other formulations, when the aqueous-based titration method was used, the results obtained were not the formation of the NE, various other records such as the formation of the emulsion, emulsion gel, and milky emulsion were found out. When we carried out the studies with 1:1 ratio of SCoS mixture from $\mathrm{F} 4$ formulation, NE was not formed. In the ratios 1:2 and 1:3 the NE is not formulated clearly. Hence, we conclude with the decision of using F1 formulation for the further studies.

\section{Particle size distribution, zeta potential, and PDI}

Particle size increases with an increase in the concentration of oil in the formulation and decreases with increase in the concentration of Smix. Among the different ratios of Smix (1:1-1:3), the ratio of Smix (1:1) having formulation F1 (1:1) was observed to form the NE which was found to have a particle size distribution of $68.83 \mathrm{~nm}$ with a PDI 1.000 , and zeta potential $-2.00 \mathrm{mV}$ with $100 \%$ transmission was selected for incorporating into tablet formulation. The optimized Smix ratio (1:1) having formulation $\mathrm{F} 1$ (1:1) was selected based on least particle size and PDI. The other parameters such as the percentage transmission and conductivity were found to be satisfactory for all the formulations. The results are displayed in Table 3. The PDI was also low; the zeta potential was found to be -2.00 , which shows that the Smix (1:1) ratio having formulation F1 (1:1) is stable. These results are evidenced in Table 3. Sample 1 has a particle size of $68.83 \mathrm{~nm}$ which is comparatively low as compared low with that of the samples 2,3 , and 4 , wherein these three samples, the particle size is found to be below $200 \mathrm{~nm}$ which is the optimal range of nanoparticles but is higher than $100 \mathrm{~nm}$, where in sample 1, the particle size is found to be below $100 \mathrm{~nm}$

Formulation and optimization of curcumin SNEDDS tablets Six formulations of SNEDDS tablets (T1-T6) were prepared by direct compression method containing a fixed proportion of curcumin

Table 3: Characterization of nanoemulsion

\begin{tabular}{llll}
\hline Samples & Particle size $(\mathbf{n m})$ & PDI & Zeta potential \\
\hline 1 & 68.83 & 1.00 & -2.00 \\
2 & 121.2 & 0.263 & -3.2 \\
3 & 143.1 & 0.250 & -3.34 \\
4 & 185 & 0.226 & -4.71 \\
\hline
\end{tabular}

PDI: Polydispersity index

Table 4: Evaluated parameters of curcumin tablets

\begin{tabular}{ll}
\hline Parameters & Results (mean \pm SD) \\
\hline Bulk density & $0.517 \pm 0.9 \mathrm{~g} / \mathrm{ml}$ \\
Tapped density & $0.604 \pm 0.15 \mathrm{~g} / \mathrm{ml}$ \\
Compressibility index & $14.1 \pm 0.29 \%$ \\
Hausner's ratio & $1.15 \pm 0.69$ \\
Angle of repose & $27.74^{\circ} \pm 0.68^{\circ}$ \\
Weight variation & $0.49 \pm 0.9 \%$ \\
Hardness & $4.21 \pm 0.5 \mathrm{~kg} / \mathrm{cm}^{2}$ \\
Thickness & $7.1 \pm 0.58 \mathrm{~mm}$ \\
Friability & $0.869 \pm 0.99 \%$ \\
\hline
\end{tabular}

SD: Standard deviation 
Table 5: Formulation and optimization of curcumin self-nanoemulsifying drug delivery system tablets

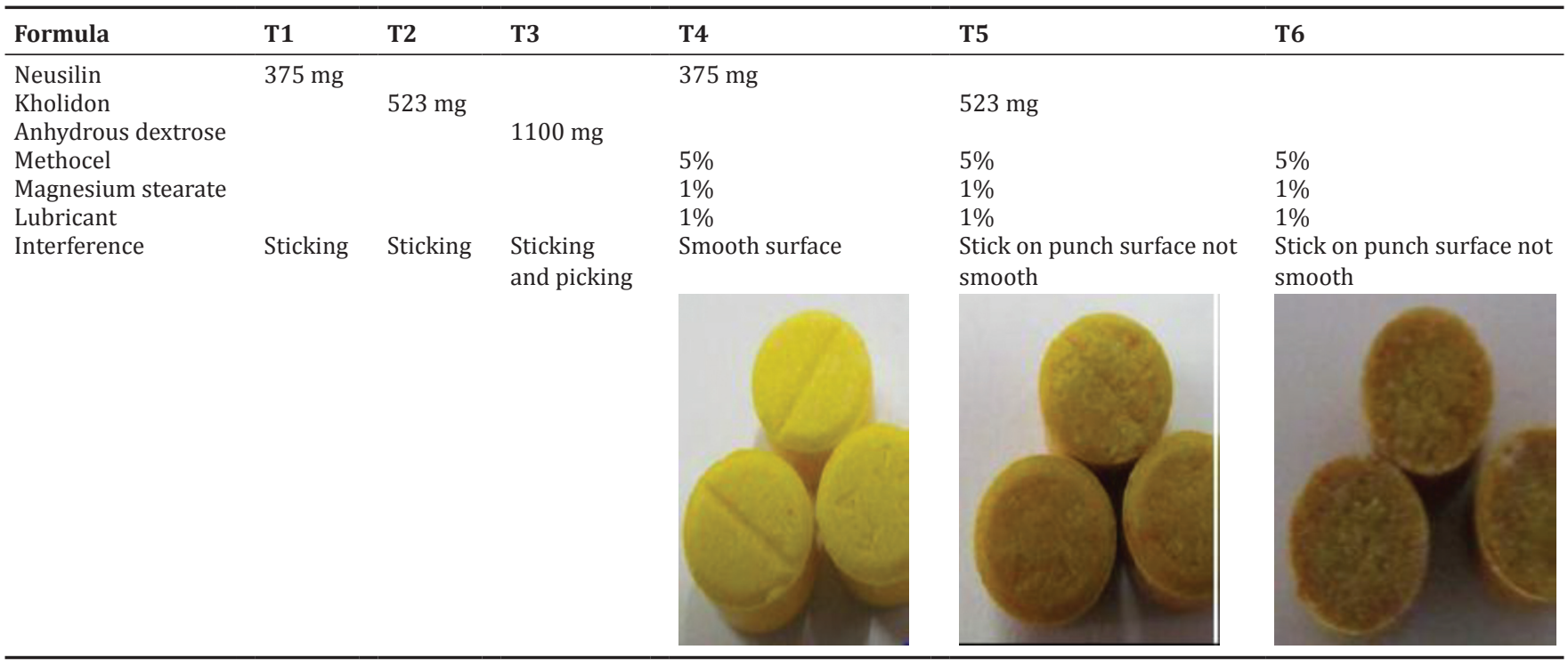

(40 mg) and the results are shown in Table 4. In formula 1 (T1), using only the Neusilin-375 mg as adsorbents, it was observed that the tablet prepared was very fragile and stick on punch, which had an irregular shape, defect tablet. This may be due to decreased concentration of binder. As a result, in formula 2 (T2), using only the kholidon-523 mg as a binder, it was shown that the tablet formed was very fragile and brittle, which gave an irregular form; in addition, some powders were observed to stick on the upper punch. As a result, in formula 3 (T3), using only anhydrous dextrose-1100 $\mathrm{mg}$ as the binder, it was shown that the tablet formed was fragile and size of the tablet is more compared to other formulation. Therefore, the addition of the binder, methocel 5\% and lubricant 2\% (talc and magnesium stearate) (formula - T4, T5, and T6), was done. Initially, NEs of the tablets prepared without curcumin formed a perfect tablet, but the tablets which were loaded with curcumin were stickier on the upper punch and the surface of the tablet was not smooth. When compared to the formula T5 with T6, the outcome was good instead, although there was still very little not perfect smoothness observed on the surface of the tablet. Moreover, formula T5 highly stickiness on the punch, which gave a rough tablet surface, was obtained. The tablet prepared using the formula T4 has perfect hardness, smooth surface and it exhibited no stickiness on the punch.

\section{Coating of tablets}

The prepared tablets were coated with pectin (1\%) using a fabricated coating pan and check the morphology of coating to do dissolution in different strength of phosphate buffer because being our target was colon, it consists of pectinase enzyme which has the ability to digest the pectin coating of the tablet that initiates drug release.

\section{Characterization of curcumin tablets}

The Micromeritic properties of tablets shown in Table 4, such as bulk density, tapped density, Hausner's ratio, compressibility, and angle of repose, are found to be within the limit. And also, friability, weight variation, hardness, and thickness also found to be within limits. The bulk density and tapped density of the SNEDDS was found to be in the range of $0.570 \mathrm{~g} / \mathrm{ml}$ and $0.604 \mathrm{~g} / \mathrm{ml}$. Since the low values of compressibility (14.4\%) and the angle of repose $<30^{\circ}$ signify good flowability of the SNEDDS, it showed that had smooth flow properties ensuring homogenous filling capacity. Friability of SNEDDS was found to be $<1 \% \mathrm{w} / \mathrm{w}$, the hardness of SNEDDS was found to be $4.21 \mathrm{~kg} / \mathrm{cm}^{2}$, the thickness of SNEDDS was found to be $4.6 \mathrm{~mm}$, and weight variation of SNEDDS was found to be $0.49 \%$. The formulation and optimization of curcumin SNEDDS tablets are given in Table 5.
Table 6: Disintegration study of the tablets

\begin{tabular}{lll}
\hline Formulation & $\mathbf{0 . 1}$ HCL $(\mathbf{2 ~ h})$ & Phosphate buffer 6.8 (1 h) \\
\hline Pectin $1 \%$ & - & $5.48 \mathrm{~min}$ \\
\hline
\end{tabular}

Table 7: Cumulative percentage release of curcumin-coated tablets

\begin{tabular}{lll}
\hline $\mathbf{p H}$ & Time in minutes & Pectin $(\mathbf{1 \%})($ mean \pm SD) \\
\hline 1.2 & 0 & 0 \\
& 30 & - \\
3 & 60 & - \\
& 90 & - \\
6.8 & 120 & $0.33 \pm 0.5$ \\
& 150 & $75.32 \pm 0.5$ \\
& 180 & $88.91 \pm 0.85$ \\
\hline
\end{tabular}

SD: Standard deviation

Table 8: Cell line studies

\begin{tabular}{llll}
\hline \multirow{2}{*}{\begin{tabular}{l} 
S.No. \\
\cline { 3 - 4 }
\end{tabular}} & $\begin{array}{l}\text { Weight of } \\
\text { spheroids }(\mathbf{m g})\end{array}$ & \multicolumn{2}{l}{ Percentage of cell viability } \\
\cline { 3 - 4 } & & Formulation & Free curcumin \\
\hline 1 & 1.56 & 68 & 70 \\
2 & 3.125 & 51 & 62 \\
3 & 6.25 & 45 & 55 \\
4 & 12.5 & 30 & 48 \\
5 & 25 & 25 & 35 \\
6 & 50 & 22 & 30 \\
7 & 100 & 21 & 28 \\
\hline
\end{tabular}

\section{Disintegration study}

Six tablets of pectin (1\%) coated tablets were placed in the disintegration test apparatus and the experiment is carried out as per procedure and $1 \%$ pectin coated tablet did not show disintegration in 0.1 HCL. However, in phosphate buffer $6.8,1 \%$ shows the complete disintegration at $5.48 \mathrm{~min}$. Because pectin is a $\mathrm{pH}$-dependent polymer, it dissolved in alkaline $\mathrm{pH}$; the results are shown in Table 6.

\section{In vitro dissolution study (release profiles)}

Coated curcumin tablets showed a complete release within $3 \mathrm{~h}$. The tablets were found to stay intact up to $\mathrm{pH} 3.0$, disintegrated at $\mathrm{pH}$ 6.8 , and the release was observed for around $2 \mathrm{~h}$. Greater than $80 \%$ of drug release was observed at $\mathrm{pH}$ 6.8. Batches prepared using pectin 
$1 \%$ showed a minimum release of $0.33 \% \pm 0.5 \%$ at $\mathrm{pH} 3$ and maximum release of $88.91 \% \pm 0.85 \%$ at $\mathrm{pH} 6.8$ (Table 6 ), and this batch was selected as an ideal and used for the further studies. The cumulative percentage release of curcumin-coated tablets is reported in Table 7

\section{Cell line study}

The viability of cells was measured using the MTT test to evaluate the cytotoxicity of curcumin on HT29 cell lines. Results of cell viability assay are shown in Table 8. The IC50 value of the formulation was found to be $21.1 \mu \mathrm{g} / \mathrm{mL}$ while that of free curcumin had $36 \mu \mathrm{g} / \mathrm{mL}$. Compared to treated cells, no cytotoxicity was observed in the cells exposed to the blank formulation. The insignificant change was observed after performing the test in a similar manner up to $72 \mathrm{~h}$.

\section{CONCLUSIONS}

The tablet formulation containing curcumin-loaded SNEDDS was prepared and evaluated. From the results obtained, the formulation (F1) were selected for the formation of the tablets and the further experimental part is carried out. The micromeritic properties of tablets, such as bulk density, tapped density angle of repose, and compressibility, were found to be within the limit.

Therefore, curcumin loaded/entrapped in SNEDDS and formulated to spheroids can be used successfully in the treatment of colorectal cancer to get the maximum therapeutic effect.

\section{ACKNOWLEDGMENT}

None.

\section{AUTHORS' CONTRIBUTIONS}

For the protocol preparation, conducting of experiment, data collection, analysis, and preparation of manuscript, all the authors played an equal role in completing this research work.

\section{CONFLICTS OF INTEREST}

The author reports no conflicts of interest.

\section{REFERENCES}

1. Henrist D, Van Bortel L, Lefebvre RA, Remon JP. In vitro and in vivo evaluation of starch-based hot stage extruded double matrix systems. J Control Release 2001;75:391-400.

2. Sinha VR, Kumria R. Polysaccharides in colon-specific drug delivery. Int J Pharm 2001;224:19-38.

3. Madhu CS, Saradha AC. Evaluation of heamagglutination and anti cancer potential from Indian dietary plants. Int J Pharm Pharm Sci 2018;10:105-8.

4. Shelat P, Mandowara VK, Gupta DG, Patel S. Formulation of curcuminoid loaded solid lipid nanoparticles in order to improve oral bioavailability. Int J Pharm Pharm Sci 2015;7:278-82.

5. Abbaspour MR, Sadeghi F, Garekani HA. Preparation and characterization of ibuprofen pellets based on eudragit RS PO and RL PO or their combination. Int J Pharm 2005;303:88-94.

6. Feng SS. Nanoparticles of biodegradable polymers for new-concept chemotherapy. Expert Rev Med Devices 2004;1:115-25.

7. Gupta AK, Pretlow TP, Schoen RE. Aberrant crypt foci: What we know and what we need to know. Clin Gastroenterol Hepatol 2007:5:526-33.

8. Abdalla A, Mäder K. Preparation and characterization of a selfemulsifying pellet formulation. Eur J Pharm Biopharm 2007;66:220-6.

9. Sahu AR, Bothara SB. Formulation and evaluation of selfmicroemulsifying drug delivery system of curcumin for enhanced solubility and dissolution. Asian J Pharm Clin Res 2015;29:893-913.

10. Gursoy RN, Benita S. Self-emulsifying drug delivery systems (SEDDS) for improved oral delivery of lipophilic drugs. Biomed Pharmacother 2004;58:173-82.
11. Basalious EB, Shawky N, Badr-Eldin SM. SNEDDS containing bioenhancers for improvement of dissolution and oral absorption of lacidipine. I: Development and optimization. Int J Pharm 2010;391:203-11.

12. Rakkappan C, Anbalagan S. Ultrasonic and FT-IR studies on aqueous biodegradable polymer blend solution. Am Eurasian J Agric Environ Sci 2009;4:281-4.

13. Chukwumezie BN, Wojcik M, Malak P, Adeyeye MC. Feasibility studies in spheronization and scale-up of ibuprofen microparticulates using the rotor disk fluid-bed technology. AAPS PharmSciTech 2002;3:E2.

14. Liew CV, Chua SM, Heng PW. Elucidation of spheroid formation with and without the extrusion step. AAPS PharmSciTech 2007;8:E70-81.

15. Cosijns A, Nizet D, Nikolakakis I, Vervaet C, De Beer T, Siepmann F, et al. Porous pellets as drug delivery system. Drug Dev Ind Pharm 2009;35:655-62.

16. Narkhede RS, Gujar KN, Gambhire VM. Design and evaluation of selfnanoemulsifying drug delivery systems for nebivolol hydrochloride. Asian J Pharm 2014;53:65-73.

17. Rowe RC, York P, Colbourn EA, Roskilly SJ. The influence of pellet shape, size and distribution on capsule filling a preliminary evaluation of three-dimensional computer simulation using a monte-carlo technique. Int J Pharm 2005;300:32-7.

18. Shaji J, Joshi V. Self-microemulsifying drug delivery system (SMEDDS) for improvingbioavailability of hydrophobic drugs and its potential to give sustained release dosageforms. Indian J Pharm Educ 2005;39:130-5.

19. Gohel MC, Parikh RK, Amin AF, Surati AK. Preparation and formulation optimization of sugar crosslinking gelatin microspheres of diclofenac sodium. Indian J Pharm Sci 2005;67:575-81.

20. Iosio T, Voinovich D, Grassi M, Pinto JF, Perissutti B, Zacchigna M, et al. Bi-layered self-emulsifying pellets prepared by co-extrusion and spheronization: Influence of formulation variables and preliminary study on the in vivo absorption. Eur J Pharm Biopharm 2008;69:686-97.

21. Kramar A, Turk S, Vrecer F. Statistical optimisation of diclofenac sustained release pellets coated with polymethacrylic films. Int J Pharm 2003;256:43-52

22. Devi SK, Thiruganesh R, Suresh S. Preparation and characterization of pectin pellets of aceclofenac for colon targeted drug delivery. J Chem Pharm Res 2010;2:361-74.

23. Shishodia S, Sethi G, Aggarwal BB. Curcumin: Getting back to the roots. Ann N Y Acad Sci 2005;1056:206-17.

24. Sousa JJ, Sousa A, Podczeck F, Newton JM. Factors influencing the physical characteristics of pellets obtained by extrusion-spheronization. Int J Pharm 2002;232:91-106.

25. Turkoglu M, Ugurlu T. In vitro evaluation of pectin-HPMC compression coated 5-aminosalicylic acid tablets for colonic delivery. Eur J Pharm Biopharm 2002;53:65-73.

26. Liu A, Lou H, Zhao L, Fan P. Validated LC/MS/MS assay for curcumin and tetrahydrocurcumin in rat plasma and application to pharmacokinetic study of phospholipid complex of curcumin. J Pharm Biomed Anal 2006;40:720-7.

27. Gou M, Men K, Shi H, Xiang M, Zhang J, Song J, et al. Curcuminloaded biodegradable polymeric micelles for colon cancer therapy in vitro and in vivo. Nanoscale 2011;3:1558-67.

28. Mohandas KM. Colorectal cancer in India: Controversies, enigmas and primary prevention. Indian J Gastroenterol 2011;30:3-6.

29. Kumar VK, Vennila S, Nalini N. Inhibitory effect of morin on DMHinduced biochemical changes and aberrant crypt foci formation in experimental colon carcinogenesis. Environ Toxicol Pharmacol 2010;29:50-7.

30. Pramod SN, Vigneshwaran V, Venkatesh YP. Immuno-modulatory effects of haeagglutinating lectins from potato (Solanum tuberosum) and garlic (Allium sativum) on human and murine lymphocytes. Int $\mathbf{J}$ Pharm Pharm Sci 2015;7:147-53.

31. Das S, Das MK. Synthesis and characterisation of thiolated jackfruit seed starch as a colonic drug delivery carrier. Int J Appl Pharm 2019;11:53-62.

32. Shaji J, Memon I. Recent advances in nanocarrier based therapeutical and diagnostic tools for colorectal cancer. Int J Curr Pharm Res 2015;7:9-16 